Check for updates

The BMJ

Cite this as: BMJ 2021;375:n2839 http://dx.doi.org/10.1136/bmi.n2839 Published: 23 November 2021

\section{Covid-19: What next for the Valneva vaccine?}

Valneva's covid-19 vaccine looked set to be another effective tool in the fight to end the pandemic. But the UK's sudden decision to cancel the company's main order of 100 million doses threw a major spanner in the works. Elisabeth Mahase asks what this means for the company and the vaccine

\section{Elisabeth Mahase}

In September, UK health secretary Sajid Javid said that the country's medicines regulator would not approve Valneva's covid-19 vaccine. The comment caused confusion among the UK's 4000 trial volunteers as well as those running the trial, as the data had not yet been reviewed.

Valneva, a French biotechnology company, specialises in vaccine development with manufacturing sites around the world. Its VLA2001 vaccine is the only whole virus, inactivated vaccine candidate in clinical trials against covid-19 in Europe-unlike most other covid-19 vaccines, it does not just target the coronavirus spike protein, but rather the whole virus. The phase III trial-being carried out in the UK-is comparing the vaccine to the Oxford AstraZeneca vaccine.

Javid's comments came as the UK announced it was cancelling its 100 million dose contract-a huge blow to the company as this was its only deal and one worth up to $€ 1.4 \mathrm{bn}$ (£1.2bn; \$1.6bn).

A month later, Valneva announced positive interim efficacy results, showing the vaccine produces significantly higher concentrations of neutralising antibodies than the Oxford AstraZeneca vaccine. Adam Finn, the trial's chief investigator, said the data "are pretty much as good as we could have hoped for in terms of the strategy towards authorisation that the UK Medicines and Healthcare Products Regulatory Authority (MHRA) have set out. We are cautiously optimistic that we will indeed achieve authorisation in the UK."

On the health secretary's announcement he added, "We don't really know why Javid said that, he hasn't actually explained, to me at least, what led to that comment.”

Despite Javid's comments, Valneva's vaccine candidate is still undergoing the MHRA's rolling submission process, with a decision expected by the end of 2021 and initial approval expected for use in 18 to 55 year olds. Discussions are ongoing with the European Medicines Agency (EMA).

On 10 November, however, the company announced an agreement with the European Commission (EC) for 60 million doses-with around 27 million doses expected in 2022 and the option for 33 million doses in 2023.

Announcing the deal, the EC hinted that its interest in the vaccine could relate to new variants. $\mathrm{EC}$ president Ursula von der Leyen said, "The contract allows for the vaccine to be adapted to new variants. Our broad portfolio will help us to fight covid-19 and its variants in Europe and beyond. The pandemic is not over. Everyone who can, should get vaccinated."

\section{Vaccine passports}

The picture is further complicated by the use of vaccination status as a requirement for travel.

Countries generally only allow entry to travellers fully vaccinated with vaccines approved by their own regulatory authorities. Where this leaves companies like Valneva is unclear.

Trial participants find themselves in a strange situation, since the experimental vaccine is still not approved anywhere. The UK government recently introduced a policy of extra vaccine doses for trial participants who want to travel, offering two doses of the widely accepted Pfizer BioNTech vaccine, eight weeks apart. Additionally, booster doses of the Pfizer vaccine are being given to eligible trial participants, in line with the booster rollout across the UK general population. Participants who get these extra doses are able to stay on the trial but will no longer be able to provide clear efficacy or safety data for the Valneva vaccine. The impact of this on any potential approval is not yet clear. ${ }^{2}$

The BMJ also understands that Valneva could include a booster dose of its vaccine in its trial early next year although, again, the viability of this is unclear now that some trial participants are understood to have doses.

Around $65 \%$ of the EU population has already had two vaccine doses, ${ }^{3}$ while just $4 \%$ of those in low income countries have received at least one dose. ${ }^{4}$ This has raised questions over why Valneva's focus for approval and rollout is on the EU.

Penny Ward, visiting professor in pharmaceutical medicine at King's College London, said that the UK's order cancellation could allow Valneva "to provide an immediate supply of the vaccine for other countries struggling with the freezer shipping requirements of other, more expensive, vaccines. Good news for Covax [the international covid vaccine alliance] and countries still awaiting supplies."

It seems Valneva's hope is that the EU deal will instil confidence in other countries to complete agreements and approve the vaccine. Since it was planning to deliver 100 million doses to the UK, there should still be a significant amount up for grabs. The EC has also highlighted that member states are able to donate the vaccine to lower and middle income countries. taken up the offer of one or two additional Pfizer 
Valneva's chief business officer Franck Grimaud said, "We are looking forward to completing the agreement and getting the rolling review with EMA underway. Our recent phase III data have allowed us to showcase the value of VLA2001 and we believe that other supply deals could follow this one.”

When asked, however, if Valneva has any plans to reach low and middle income countries, the company did not respond.

Competing interests: EM is a participant in the Valneva covid-19 vaccine trial.

1 Mahase E. Covid-19: Valneva's vaccine produces stronger immune response than AstraZeneca's, company reports. BMJ2021;375:n2551. doi: 10.1136/bmj.n2551 pmid: 34663573

2 Mahase E. Covid-19: Trial participants are offered approved vaccines so they can travel abroad. BMJ2021;375:n2474. doi: 10.1136/bmi.n2474 pmid: 34625450

3 European Centre for Disease Prevention and Control covid-19 vaccine tracker. https://vaccinetracker.ecdc.europa.eu/public/extensions/COVID-19/vaccine-tracker.htm|\#uptake-tab.

4 Coronavirus vaccinations. https://ourworldindata.org/covid-vaccinations.

This article is made freely available for use in accordance with BMJ's website terms and conditions for the duration of the covid-19 pandemic or until otherwise determined by BMJ. You may use, download and print the article for any lawful, non-commercial purpose (including text and data mining) provided that all copyright notices and trade marks are retained. 